\title{
Effect of treadmill exercise on spatial navigation impairment associated with cerebellar Purkinje cell loss following chronic cerebral hypoperfusion
}

\author{
JAE-MIN LEE ${ }^{1}$, CHANG-JU KIM ${ }^{1}$, JONG-MIN PARK ${ }^{2}$, MIN KYUNG SONG ${ }^{2}$ and YOUN-JUNG KIM ${ }^{3}$ \\ ${ }^{1}$ Department of Physiology, College of Medicine; ${ }^{2}$ Department of Nursing, Graduate School; ${ }^{3}$ Department of \\ Basic Nursing Science, College of Nursing Science, Kyung Hee University, Seoul 02447, Republic of Korea
}

Received November 27, 2017; Accepted March 20, 2018

DOI: $10.3892 / \mathrm{mmr} .2018 .8893$

\begin{abstract}
In addition to roles in motor coordination, the cerebellum is also associated with cognitive function. The aim of the present study was to investigate the effect of treadmill exercise on spatial navigation deficit induced by chronic cerebral hypoperfusion $(\mathrm{CCH})$. Furthermore, whether decreased loss of Purkinje cells, which contain the calcium-binding protein in the posterior lobe of the cerebellum, attenuates the spatial navigation deficit induced by $\mathrm{CCH}$ was also investigated. Wistar rats were randomly divided into three groups: Sham group, bilateral common carotid arteries occlusion (BCCAO) group and a BCCAO + exercise (Ex) group. The rats in the $\mathrm{BCCAO}+$ Ex group ran on a treadmill for $30 \mathrm{~min}$ once a day for 8 weeks, starting at 4 weeks post-birth. $\mathrm{CCH}$ was induced by performing BCCAO at 12 weeks post-birth. The Morris water maze test was performed to determine the spatial navigation function of the rats. To investigate the histological features of the cerebellum in all of the experimental groups post-treatment, terminal deoxynucleotidyl transferase dUTP nick end labeling staining, as well as immunohistochemical analysis revealing the expression of calbindin, parvalbumin, glial fibrillary acidic protein, ionized calcium-binding adaptor molecule 1 and caspase-3, was performed. The results of the present study revealed that treadmill exercise improved spatial navigation, decreased the expression of reactive astrocytes and microglial cells, and decreased apoptotic rates in the cerebellar vermis post- $\mathrm{CCH}$. Treadmill exercise also attenuated the loss of Purkinje cells following $\mathrm{CCH}$. The number of Purkinje cells was revealed to be negatively correlated with spatial navigation performance.
\end{abstract}

Correspondence to: Professor Youn-Jung Kim, Department of Basic Nursing Science, College of Nursing Science, Kyung Hee University, 26 Kyungheedae-ro, Jung-gu, Seoul 02447, Republic of Korea

E-mail: yj129@khu.ac.kr

Key words: vascular dementia, chronic cerebral hypoperfusion, cerebellum, treadmill exercise, cognitive impairment
These results indicate that treadmill exercise may attenuate spatial navigation impairment via inhibition of Purkinje cell loss in the posterior lobe of the cerebellum following $\mathrm{CCH}$. Therefore, treadmill exercise may represent a therapeutic strategy for the treatment of patients with spatial navigation impairment following $\mathrm{CCH}$.

\section{Introduction}

The role of the cerebellum was previously considered to be confined to movement, along with the cortex and basal ganglia; however, it has recently been redefined to represent a broader area of functions, including cognitive functions $(1,2)$. The cerebellum receives and sends information from various brain regions, including the hypothalamus, hippocampus and cortex (3). The function of the cerebellum is strongly associated with the hippocampus, and the cerebellum has been revealed to affect hippocampal activity, including spatial navigation and working memory (3-5). Although it has not been fully determined, the cerebellum may affect the hippocampus in two ways (1). The cerebellar brain region is primarily associated with cognitive functioning, particularly spatial navigation and executive tasks, and is located in the posterior lobe of the cerebellum. A previous neuroimaging study has demonstrated that cognitive functions are associated with the posterior lobe of the cerebellum (6). Damage to the posterior lobe of the cerebellum has been revealed to be associated with impairment of spatial working memory, and transgenic mice with cerebellar dysfunction have been demonstrated to exhibit spatial navigation deficit $(7,8)$.

Rats with Purkinje cells removed in the cerebellum exhibited impaired spatial navigation performance following analysis using the rotor-rod and Morris water maze tests (9). Purkinje cells are located the Purkinje layer of the cerebellum, which exhibits the greatest abundance of calcium-binding proteins in the cerebellum, such as calbindin D28k and parvalbumin. Such proteins have important roles in physiological processes, including cell cycle regulation, muscle contraction and the regulation of intracellular $\mathrm{Ca}^{2+}$ concentration associated with apoptosis (10). Purkinje cells, which have important roles in cerebellar function, are particularly vulnerable to damage in ischemia (11). Purkinje cell death induced by ischemia in the 
cerebellum has been reported to be induced by excitotoxicity due to glutamate release and intracellular calcium (12).

Chronic cerebral hypoperfusion $(\mathrm{CCH})$ is a major pathological feature of vascular dementia that results in progressive cognitive impairment due to interference in the circulatory system (13-15). CCH has been demonstrated to induce hypoxia and oxidative stress, as well as cause inflammation of the cerebral cortex, white matter, hippocampus and striatum, resulting in impaired cognitive function (16-19). However, the pathological mechanism of $\mathrm{CCH}$ has not been fully determined. Research concerning the effects of $\mathrm{CCH}$ on the cerebellum and determining novel therapeutic strategies to enhance spatial navigation of patients suffering from $\mathrm{CCH}$ has been limited.

Treadmill exercise has been demonstrated to ameliorate neurological impairments following various brain disorders, including ischemia and Alzheimer's disease (20,21). Treadmill exercise has also been revealed to improve cognitive function by reducing the apoptosis rate of neurons and the reactivity of astrocytes in the cerebellum following transient global ischemia (22), and also protect against age-associated Purkinje cell loss (23). The aim of the present study was to investigate whether $\mathrm{CCH}$ induces a loss of Purkinje cells, and to investigate the effect of treadmill exercise on spatial navigation impairment associated with $\mathrm{CCH}$.

\section{Materials and methods}

Experimental animals. Male Wistar rats (n=30; weight $80 \pm 10 \mathrm{~g}$, 3-weeks old, Orient Bio, Inc., Seongnam, Korea) were used in the present study. The rats were housed under controlled temperature $\left(20 \pm 2^{\circ} \mathrm{C}\right)$, humidity $(60 \pm 5 \%)$, and lighting conditions (7:00 a.m. to 7:00 p.m.) with food and water available ad libitum. All animal experimental procedures conformed to the regulations stipulated by the National Institutes of Health (Bethesda, MD, USA) (24) and the guidelines of the Korean Academy of Medical Science (Seoul, Korea). The present study was approved by the Kyung Hee University Institutional Animal Care and Use Committee [Seoul, Korea; KHUASP (SE)-16-149]. The rats were randomly divided into three groups: Sham group $(n=10)$, bilateral common carotid arteries occlusion $(\mathrm{BCCAO})$ group $(\mathrm{n}=10)$ and a $\mathrm{BCCAO}+$ treadmill exercise $(\mathrm{BCCAO}+\mathrm{Ex})$ group $(\mathrm{n}=10)$.

Treadmill exercise protocol. The rats in the BCCAO + Ex group were made to run on a treadmill for $30 \mathrm{~min}$ once a day for 8 weeks starting at 4 weeks post-birth, according to a previously described method (21). The treadmill exercise load consisted of running at $2 \mathrm{~m} / \mathrm{min}$ for the first $5 \mathrm{~min}, 3 \mathrm{~m} / \mathrm{min}$ for the following $5 \mathrm{~min}$ and $5 \mathrm{~m} / \mathrm{min}$ for the last $20 \mathrm{~min}$, at 0 degrees of inclination. The rats in the non-exercise groups were placed on the treadmill without being made to run for the same time period as the exercise group.

BCCAO. Rats were anesthetized via subcutaneous injection of $250 \mathrm{mg} / \mathrm{kg}$ tribromoethanol (Avertin ${ }^{\circledR}$; Sigma-Aldrich; Merck KGaA, Darmstadt, Germany). BCCAO was performed to induce $\mathrm{CCH}$ and was performed carefully to avoid damage to the vagus nerve and surrounding tissues. Both carotid arteries were exposed by a ventral midline incision and double ligated with 3-0 silk (Ailee, Seoul, Korea) immediately below the carotid bifurcation. The rats in the sham group underwent the same operation procedure without vessel ligation.

Open field test. Activity was determined using the open field test. As a previously described method (25), the rats were randomly assigned to an order of testing and placed in a white square open-field arena $(100 \times 100 \mathrm{~cm})$ made of wood, enclosed by $40-\mathrm{cm}$-high walls and exposed to strong illumination (200 lux). The arena was divided into 25 squares $(20 \times 20 \mathrm{~cm})$, consisting of 9 central and 16 peripheral squares. The rats were placed in the center of the arena and were allowed to explore the environment for $1 \mathrm{~min}$. Following this time, the number of squares crossed was recorded for $5 \mathrm{~min}$.

Morris water maze test. In order to investigate the spatial navigation in rats, the latency time in the Morris water maze test was determined according to a previously described method (1). The Morris water maze test consisted of a circular pool (painted white, $200 \mathrm{~cm}$ diameter, $60 \mathrm{~cm}$ high) filled with water $\left(22 \pm 2^{\circ} \mathrm{C}, 37 \mathrm{~cm}\right.$ deep) that was made opaque by the addition $1 \mathrm{~kg}$ skim milk powder. A platform $(15 \mathrm{~cm}$ diameter, $35 \mathrm{~cm}$ high) was submersed $2 \mathrm{~cm}$ below the water surface in one of four quadrants in the pool. A video recorder was hung from the ceiling and was connected to a tracking device (SMART; Panlab, Barcelona, Spain). The animals were subjected to three trials per session. In each session, the rats were permitted to search for the platform for $60 \mathrm{sec}$. If the rat located the platform, the animals were permitted to remain on the platform for a further $10 \mathrm{sec}$. If the rat did not locate the platform within $60 \mathrm{sec}$, the rat was guided to the platform and permitted to remain for a further $10 \mathrm{sec}$. The latency times taken to locate the submerged platform were recorded. The animals were tested in this way for a total of 4 days with 3 trials per day.

Immunohistochemistry. A total of 6 animals per group were used for immunohistochemistry staining. Serial sagittal sections $(40 \mu \mathrm{m})$ were obtained using a freezing microtome (-20 to $-25^{\circ} \mathrm{C}$; Leica Microsystems $\mathrm{GmbH}$, Wetzlar, Germany). Immunohistochemistry was performed to investigate the expression of glial fibrillary acidic protein (GFAP), ionized calcium-binding adaptor molecule 1 (Iba-1), calbindin D28k and parvalbumin in each cerebellar vermis. Free-floating sections were initially incubated in $3 \% \mathrm{H}_{2} \mathrm{O}_{2}$ for $30 \mathrm{~min}$ at room temperature. Following this, the sections were incubated in blocking solution ( $1 \%$ bovine serum albumin and $0.2 \%$ Triton X-100; Vector Laboratories, Inc., Burlingame, CA, USA) for $2 \mathrm{~h}$ at room temperature $\left(27^{\circ} \mathrm{C}\right)$. The sections were subsequently incubated overnight with the following primary antibodies: GFAP (1:500; AB5804; Chemicon; Merck KGaA), Iba-1 (1:500; ab178846; Abcam, Cambridge, UK), calbindin D28k (1:500; ab11426; Abcam), parvalbumin (1:1,000; ab11427; Abcam), and caspase-3 (1:500; sc-56053; Santa Cruz Biotechnology, Inc., Dallas, TX, USA) overnight at $4^{\circ} \mathrm{C}$. Following this, sections were incubated with biotinylated mouse (BA-2000), goat (BA-9500) and rabbit (BA-1100) secondary antibodies (1:200; Vector Laboratories, Inc., Burlingame, CA, USA) for $1 \mathrm{~h}$ at room temperature $\left(27^{\circ} \mathrm{C}\right)$. The sections were then incubated with an avidin-biotin-peroxidase complex (1:1,000; Vector Laboratories, Inc.) for $1 \mathrm{~h}$ at room temperature 
$\left(27^{\circ} \mathrm{C}\right)$. For staining, the sections were incubated in a solution consisting of $0.02 \%$ DAB and $0.03 \% \mathrm{H}_{2} \mathrm{O}_{2}$ in $50 \mathrm{mM}$ Tris- $\mathrm{HCl}$ (pH 7.6) for approximately $5 \mathrm{~min}$, following which they were washed with PBS and mounted onto gelatin-coated slides. Cover slips were mounted using Permount ${ }^{\circledR}$ (Fisher Scientific). Sections were assessed in a quantitative fashion, according to a micro-densitometrical method based on optical density using Image Pro ${ }^{\circledR}$ Plus software version 6.0 (Media Cybernetics, Bethesda, MD, USA). The number of positive cells per section was counted in 5 random fields from every specimen with a Nikon Eclipse 80i microscope (magnification, x40; Nikon Corporation, Tokyo, Japan).

Terminal deoxynucleotidyl transferase dUTP nick end labeling (TUNEL) staining. To visualize DNA fragmentation, which is a marker of apoptosis, TUNEL staining was performed using an in Situ Cell Death Detection kit with fluorescein (Roche Diagnostics GmbH, Mannheim, Germany). Serial sagittal brain sections $(40 \mu \mathrm{m})$ were fixed in $4 \%$ paraformaldehyde at room temperature for $15 \mathrm{~min}$, post-fixed in ethanol-acetic acid (2:1) for $5 \mathrm{~min}$ at $-20^{\circ} \mathrm{C}$ and then rinsed with PBS. Following this, sections were incubated with proteinase $\mathrm{K}(100 \mu \mathrm{g} / \mathrm{ml})$, rinsed with $\mathrm{PBS}$ and incubated in $3 \% \mathrm{H}_{2} \mathrm{O}_{2}$ for $30 \mathrm{~min}$ at room temperature $\left(27^{\circ} \mathrm{C}\right)$. Sections were subsequently permeabilized using $0.5 \%$ Triton $\mathrm{X}-100$ for $1 \mathrm{~h}$ at room temperature $\left(27^{\circ} \mathrm{C}\right)$, rinsed again and incubated in the TUNEL reaction mixture for $1 \mathrm{~h}$ at $37^{\circ} \mathrm{C}$. The sections were rinsed and visualized using a Converter-POD for $1 \mathrm{~h}$ in a humidified $37^{\circ} \mathrm{C}$ chamber. The sections were incubated in a solution containing in $50 \mathrm{mM}$ Tris- $\mathrm{HCl}$ (pH 7.6) containing $0.03 \%$ DAB, $40 \mathrm{mg} / \mathrm{ml}$ nickel chloride, and $0.03 \%$ hydrogen peroxide. The slides were counterstained with Nissl staining and mounted onto a gelatin coated slide. The slides were coverslipped with Permount (Thermo Fisher Scientific, Inc., Waltham, MA, USA).

Statistical analysis. Data are presented as the mean \pm standard error of the mean. SPSS software version 23.0 (IBM Corp., Armonk, NY, USA) was used for statistical analysis. Statistical analysis was performed using one-way analysis followed by Tukey's post-hoc test or Pearson's correlation analysis. $\mathrm{P}<0.05$ was considered to indicate a statistically significant with 3-6 independent experiments.

\section{Results}

Treadmill exercise alleviates spatial navigation impairment induced by $\mathrm{CCH}$. The Morris water maze test was performed to investigate the effect of treadmill exercise on spatial navigation impairment induced by $\mathrm{CCH}$. The results indicated that the BCCAO group demonstrated an increased escape latency time compared with the sham group $(\mathrm{P}<0.05$; Fig. 1). However, the $\mathrm{BCCAO}+\mathrm{Ex}$ group demonstrated a significantly shorter escape latency time compared with the BCCAO group on days 3 and 4 of testing $(\mathrm{P}<0.05$; Fig. 1$)$.

Treadmill exercise reduces levels of reactive astrocytes and microglial activation in the cerebellum. To investigate the effect of treadmill exercise on glial cell activation, immunohistochemistry was performed. Photomicrographs of GFAP- and Iba-1-positive cells in the posterior regions of the
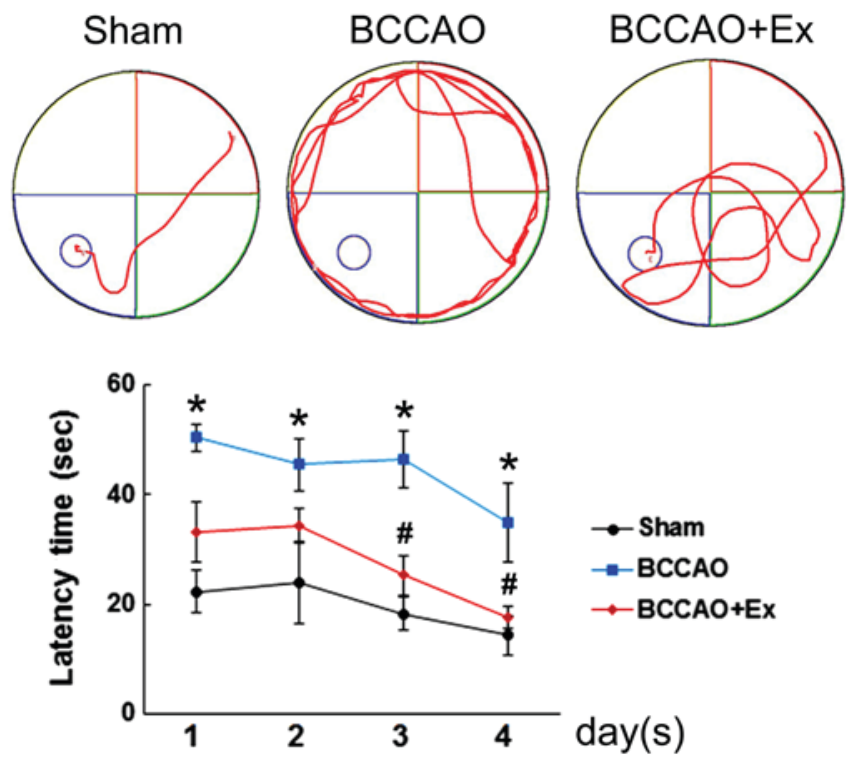

Figure 1. Effect of treadmill exercise on spatial navigation impairment. Spatial navigation impairment in rats was examined by Morris water maze testing. Representative paths and latency time taken to locate the hidden platform for each group are presented. Data are presented as the mean \pm standard error of the mean. ${ }^{*} \mathrm{P}<0.05$ vs. sham group; ${ }^{~} \mathrm{P}<0.05$ vs. BCCAO group. BCCAO, bilateral common carotid arteries occlusion; Ex, exercise.

cerebellar vermis are presented in Fig. 2. GFAP, a marker of reactive astrocytes, was revealed to be significantly increased following cerebral ischemia (26); however, this effect was significantly attenuated following treadmill exercise $(\mathrm{P}<0.001$; Fig. 2A). Iba-1 is a specific marker of microglia. Following transient focal cerebral ischemia induced by BCCAO, Iba-1 expression was demonstrated to be significantly increased in the BCCAO group compared with the sham group. However, this effect was significantly attenuated following treadmill exercise $(\mathrm{P}<0.001$; Fig. 2B).

Treadmill exercise reduces apoptotic cell death in the cerebellum. Apoptotic neuronal cell death was determined via TUNEL analysis, which detects DNA fragmentation (27). The results demonstrated that the $\mathrm{BCCAO}+$ Ex group exhibited a significantly decreased number of TUNEL-positive cells in the posterior region compared with the BCCAO group $(\mathrm{P}<0.001$; Fig. 3).

Caspase-3, a member of the caspase family, has an important function in apoptotic cell death (28). The BCCAO + Ex group demonstrated a significantly decreased number of caspase-3-positive cells in the posterior region compared with the BCCAO group ( $\mathrm{P}<0.001$; Fig. 3). Furthermore, the BCCAO group demonstrated increased TUNEL and caspase-3-positive cells in the granular and molecular layers of the cerebellar vermis compared with the sham group (Fig. 3).

Treadmill exercise attenuates the loss of Purkinje cells in the cerebellum. Calbindin D28k has regulatory roles in motor coordination, sensory integration and important functions of Purkinje cells (29). The BCCAO + Ex group demonstrated a significantly increased number of calbindin-positive Purkinje cells in the posterior regions compared with the BCCAO group $(\mathrm{P}<0.001$; Fig. 4A). However, calbindin D28k-positive 

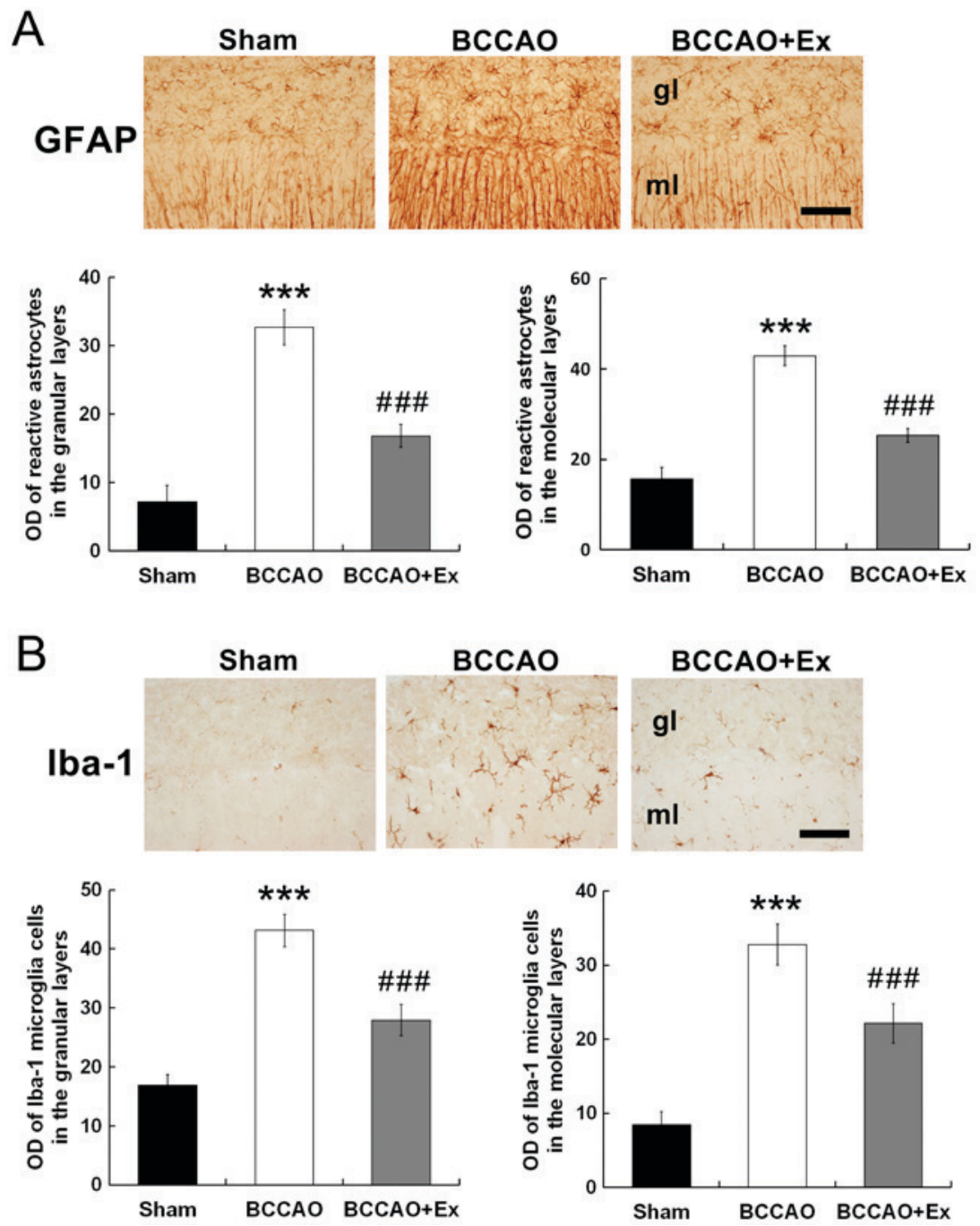

BCCAO

BCCAO+Ex

gl
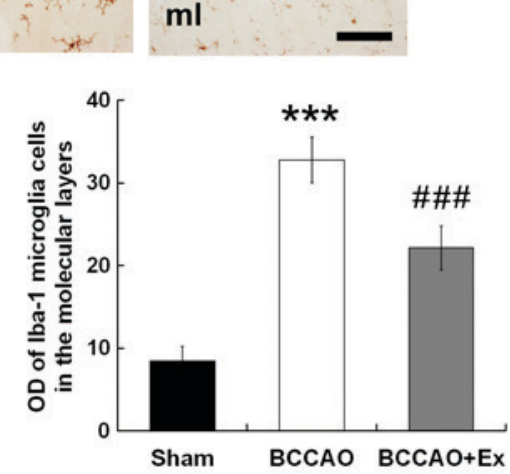

Figure 2. Effect of treadmill exercise on reactive astrocytes and microglial activation in the cerebellum. (A) Representative photomicrographs and OD of GFAP immunostaining in the granular and molecular layers of the cerebellum. Scale bar, $50 \mu \mathrm{m}$. (B) Representative photomicrographs and OD of Iba-1 immunostaining in the granular and molecular layers of the cerebellum. Scale bar, $50 \mu \mathrm{m}$. Data are presented as the mean \pm standard error of the mean. ${ }^{* * *} \mathrm{P}<0.001$ vs. sham group; ${ }^{\# \#} \mathrm{P}<0.001$ vs. BCCAO group. OD, optical density; GFAP, glial fibrillary acidic protein; Iba-1, ionized calcium-binding adaptor molecule 1; $\mathrm{BCCAO}$, bilateral common carotid arteries occlusion; Ex, exercise; gl, granular layer; ml, molecular layer.

Purkinje cells did not demonstrate a correlation with the latency time in the Morris water maze test $(\mathrm{r}=-0.278, \mathrm{P}=0.316$; Fig. 4B).

Parvalbumin, a small protein that is involved in $\mathrm{Ca}^{2+}$ signaling, protects neurons from cell death via suppression of intracellular $\mathrm{Ca}^{2+}$ concentrations (29). The BCCAO + Ex group demonstrated a significantly higher number of parvalbumin-positive Purkinje cells in the posterior region compared with the BCCAO group ( $\mathrm{P}<0.001$; Fig. 4A). Furthermore, the number of parvalbumin-positive Purkinje cells was revealed to be negatively correlated with the latency time in the Morris water maze test ( $r=-0.561, \mathrm{P}=0.030$; Fig. 4B).

\section{Discussion}

Physical exercise has numerous positive effects on brain functions, and running exercises have been revealed to improve various neurodegenerative disorders, such as ischemia, Alzheimer's and Parkinson's disease $(20,30,31)$. In the present study, a low-intensity form of treadmill exercise was employed.
The low intensity exercise used in the present study represents $\sim 50-60 \%$ of maximum oxygen uptake (32). Previous studies have demonstrated that low-intensity treadmill exercise induced positive effects on neurogenesis in the hippocampal dentate gyrus as well as the recovery of cognitive function in stroke models $(33,34)$. The present study was performed to investigate the effect of treadmill exercise on spatial navigation impairment associated with cerebellar Purkinje cell loss following $\mathrm{CCH}$. The results revealed that treadmill exercise significantly ameliorated the spatial navigation performance of rats in the Morris water maze following $\mathrm{CCH}$. This result is consistent with previous studies, which demonstrated that treadmill exercise alleviated spatial navigation impairment in the radial 8 arm maze and Morris water maze $(31,35)$. Thus, the results of the present study indicate that treadmill exercise may attenuate spatial navigation performance following $\mathrm{CCH}$.

Animal activity by open field test was investigated in the present study (data not shown). The results demonstrated that the activity score in the open field test was not significantly different among the different experimental groups. The present 

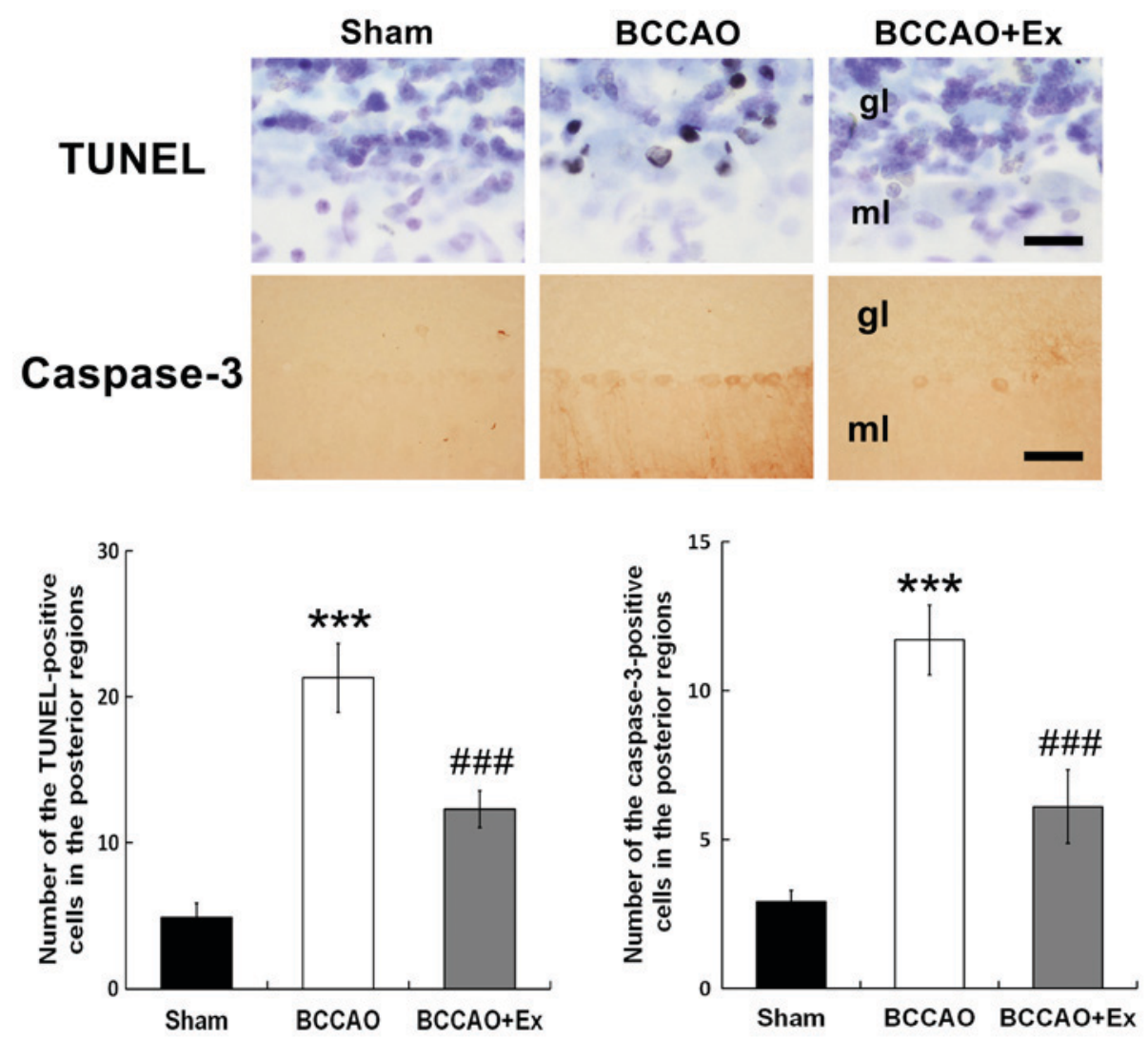

Figure 3. Effect of treadmill exercise on apoptotic cell death in the cerebellum. Representative photomicrographs of immunostaining and the numbers of TUNEL- and caspase-3-positive cells in the cerebellar vermis are presented. The scale bars represent 10 and $50 \mu \mathrm{m}$ for TUNEL and caspase-3 staining images, respectively (blue staining: Nissl substance stained by Cresyl violet; black staining: TUNEL staining). Data are presented as the mean \pm standard error of the mean. ${ }^{* * *} \mathrm{P}<0.001$ vs. sham group; ${ }^{\# \# *} \mathrm{P}<0.001$ vs. BCCAO group. TUNEL, terminal deoxynucleotidyl transferase dUTP nick end labeling; BCCAO, bilateral common carotid arteries occlusion; Ex, exercise; gl, granular layer; ml, molecular layer.

study did not include a sham + Ex group, so it is difficult to expect the effect of exercise in normal group. Heo et al (21) previously revealed that treadmill exercise in normal mice did not exhibit a significant effect on short-term memory. Furthermore, an additional study demonstrated that the number of incorrect choices made in a radial 8-arm maze test by rats in a sham + Ex group was not decreased compared with the sham group (36). The present study investigated whether involuntary exercise attenuates spatial navigation impairment via inhibition of Purkinje cell loss in the cerebellum following $\mathrm{CCH}$. Therefore, a sham + Ex group was not deemed necessary for inclusion in the study design.

Reactive astrocytes and microglia activation following brain injury enhance neuronal death $(37,38)$. Reactive astrocytes result in neuroinflammation, neurotoxic function and the formation of a glial scar (39). Activation of microglial cells, the resident immune cells of the central nervous system, is an important factor involved in central nervous system injury responses and neuronal cell death (38). The results of the present study revealed that treadmill exercise decreased the levels of reactive astrocytes, and activation of microglial cells in the posterior lobe of the cerebellum are consistent with previous studies $(40,41)$. Reactive astrocytes following brain damage have previously been demonstrated to result in increased GFAP expression in neurodegenerative diseases, such as Alzheimer's disease and ischemia (41). Activated microglial cells have been implicated in neuronal apoptosis following ischemic stroke, and enhanced expression of Iba-1 has previously been revealed to be upregulated following transient middle cerebral artery occlusion (27). Therefore, the suppression of reactive astrocytes and microglia activation may represent the underlying neuroprotective effect of treadmill exercise against neuronal damage in the posterior lobe of the cerebellum.

Several studies have demonstrated that cerebral ischemia animal models exhibit increased apoptotic cell death in the brain $(28,42)$. TUNEL and caspase-3-positive cells have also been revealed to be increased in ischemic brains (38). In the present study, treadmill exercise significantly decreased the levels of TUNEL- and caspase-3-positive cells in the posterior region of the cerebellum. Marques-Aleixo et al (43) revealed that a rat treadmill endurance training group demonstrated significantly increased expression levels of the anti-apoptotic protein Bcl-2 in the cerebellum compared with the expression levels exhibited by the sedentary group. A further study revealed that treadmill exercise reduced the rate of apoptosis in the cerebellums of autistic rats (44). The results of the present study indicated that treadmill exercise significantly decreased apoptosis in the cerebellum of rats suffering from $\mathrm{CCH}$ and may have a role in attenuating the loss of Purkinje cells.

Intracellular $\mathrm{Ca}^{2+}$ in neurons is important for neural excitability, as calcium enters Purkinje cells during action potentials following activation of voltage-gated $\mathrm{Ca}^{2+}$ channels (45). Cerebral ischemia is reported to induce an increase in intracellular $\mathrm{Ca}^{2+}$ levels, which subsequently results in a 


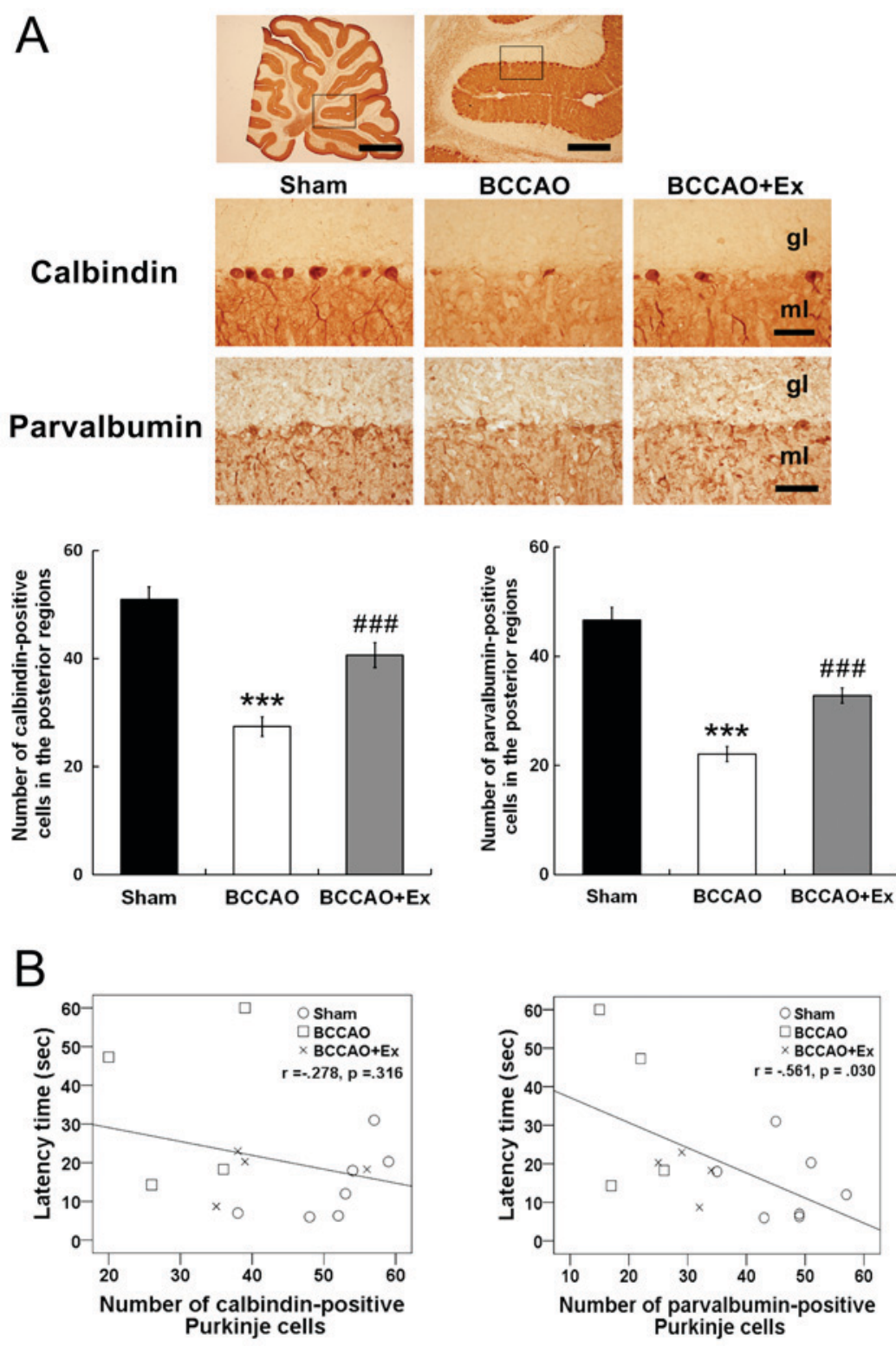

Figure 4. Treadmill exercise attenuates chronic cerebral hypoperfusion-induced Purkinje cell loss in the posterior regions of the cerebellum. (A) Representative photomicrographs of immunostaining and the number of calbindin- and parvalbumin-positive cells in the posterior lobe of the cerebellar vermis are presented. The scale bars represent $1,000 \mu \mathrm{m}$ for the upper left image, $200 \mu \mathrm{m}$ for the upper right image and $50 \mu \mathrm{m}$ for the lower calbindin and parvalbumin staining images. (B) Pearson's correlation analysis was performed to determine the correlation between the number of calcium binding protein-positive Purkinje cells and latency time in Morris water maze tests. Data are presented as the mean \pm standard error of the mean. ${ }^{* * * *} \mathrm{P}<0.001$ vs. sham group; ${ }^{\# \# \#} \mathrm{P}<0.001 \mathrm{vs}$. BCCAO group. BCCAO, bilateral common carotid arteries occlusion; Ex, exercise; gl, granular layer; ml, molecular layer.

marked increase in the activation of proteases, thus resulting in apoptotic cell death (46). Calbindin D28k and parvalbumin regulate motor coordination and sensory integration, which represent important functions of Purkinje cells (47). Thus, the regulation of intracellular $\mathrm{Ca}^{2+}$ levels by calcium-binding proteins is important for the neuronal viability in the brain (10). The results of the present study demonstrated that treadmill exercise significantly attenuated the loss of calbindin D28k- and parvalbumin-positive Purkinje cells following $\mathrm{CCH}$. These results are consistent with a previous study that revealed that treadmill exercise attenuated the loss of calbindin D28k-positive Purkinje cells in the cerebellar vermis of rats suffering from amyloid $\beta_{25-35}$-induced Alzheimer's disease (41). Investigation into whether there was a correlation between loss of Purkinje cells and cognitive impairment revealed that there was a significant negative correlation between the number of parvalbumin-positive Purkinje cells and spatial navigation ability. Furthermore, a marginal negative correlation was demonstrated between the number of calbindin D28k-positive Purkinje cells and spatial navigation ability, though this correlation was not significant. Consistent with these observations, a previous study investigated loss of Purkinje cells in the cerebellum by administration of OX7-saporin, and the results revealed that rats exhibited an impaired spatial navigation performance in the Morris water maze test compared with the control group (48). Thus, the results of the present study indicated that treadmill exercise decreased the loss of the Purkinje cells in the cerebellum following $\mathrm{CCH}$ in rats and that a negative correlation may exist between loss of Purkinje cells and spatial navigation performance. 
In conclusion, the results of the present study indicate that treadmill exercise may exert a neuroprotective effect against the loss of Purkinje cells via the suppression of glial cells and apoptosis. Therefore, treadmill exercise may have potential as a therapeutic intervention strategy for the attenuation of memory impairment in patients with $\mathrm{CCH}$.

\section{Acknowledgements}

Not applicable.

\section{Funding}

This present study was supported by National Research Foundation of Korea, which was funded by the Ministry of Education, Science and Technology (Seoul, Korea; grant no. NRF-2017R1A2B4012775).

\section{Availability of data and materials}

The analyzed data sets generated during the study are available from the corresponding author on reasonable request.

\section{Authors' contributions}

JL, JP and YK designed the experiments and the study. JL and MS looked after the animals and performed the experiments. CK participated in designing and discussing the study. JL, JP and YK wrote the manuscript. All authors read and approved the final manuscript.

\section{Ethics approval and consent to participate}

The present study was approved by the Kyung Hee University Institutional Animal Care and Use Committee [Seoul, Korea; KHUASP (SE)-16-149].

\section{Consent for publication}

Not applicable.

\section{Competing interests}

The authors declare that they have no competing interests.

\section{References}

1. Rochefort C, Lefort $\mathrm{J}$ and Rondi-Reig L: The cerebellum: A new key structure in the navigation system. Front Neural Circuits 7 35, 2013.

2. Taylor JA and Ivry RB: Cerebellar and prefrontal cortex contributions to adaptation, strategies, and reinforcement learning. Prog Brain Res 210: 217-253, 2014.

3. Yu W and Krook-Magnuson E: Cognitive collaborations: Bidirectional functional connectivity between the cerebellum and the hippocampus. Front Syst Neurosci 9: 177, 2015.

4. Onuki Y, Van Someren EJ, De Zeeuw CI and Van der Werf YD: Hippocampal-cerebellar interaction during spatio-temporal prediction. Cereb Cortex 25: 313-321, 2015.

5. Lalonde R and Botez MI: The cerebellum and learning processes in animals. Brain Res Brain Res Rev 15: 325-332, 1990.

6. Stoodley CJ and Schmahmann JD: Functional topography in the human cerebellum: A meta-analysis of neuroimaging studies. Neuroimage 44: 489-501, 2009.
7. Burguière E, Arleo A, Hojjati Mr, Elgersma Y, De Zeeuw CI, Berthoz A and Rondi-Reig L: Spatial navigation impairment in mice lacking cerebellar LTD: A motor adaptation deficit? Nat Neurosci 8: 1292-1294, 2005.

8. Tomlinson SP, Davis NJ, Morgan HM and Bracewell RM: Cerebellar contributions to spatial memory. Neurosci Lett 578: 182-186, 2014.

9. Martin LA, Goldowitz D and Mittleman G: The cerebellum and spatial ability: Dissection of motor and cognitive components with a mouse model system. Eur J Neurosci 18: 2002-2010, 2003.

10. Zhao S, Chen N, Yang Z, Huang L, Zhu Y, Guan S, Chen Q and Wang JH: Ischemia deteriorates the spike encoding of rat cerebellar Purkinje cells by raising intracellular $\mathrm{Ca} 2+$. Biochem Biophys Res Commun 366: 401-407, 2008.

11. Kelley MH, Taguchi N, Ardeshiri A, Kuroiwa M, Hurn PD, Traystman RJ and Herson PS: Ischemic insult to cerebellar Purkinje cells causes diminished GABAA receptor function and allopregnanolone neuroprotection is associated with GABAA receptor stabilization. J Neurochem 107: 668-678, 2008.

12. Welsh JP, Yuen G, Placantonakis DG, Vu TQ, Haiss F, O'Hearn E, Molliver ME and Aicher SA: Why do purkinje cells die so easily after global brain ischemia? Aldolase C, EAAT4, and the cerebellar contribution to posthypoxic myoclonus. Adv Neurol 89: 331-359, 2002.

13. Román GC, Erkinjuntti T, Wallin A, Pantoni L and Chui HC: Subcortical ischaemic vascular dementia. Lancet Neurol 1: 426-436, 2002.

14. O'Brien JT, Erkinjuntti T, Reisberg B, Roman G, Sawada T, Pantoni L, Bowler JV, Ballard C, DeCarli C, Gorelick PB, et al: Vascular cognitive impairment. Lancet Neurol 2: 89-98, 2003.

15. Kalaria RN, Maestre GE, Arizaga R, Friedland RP, Galasko D, Hall K, Luchsinger JA, Ogunniyi A, Perry EK, Potocnik F, et al: Alzheimer's disease and vascular dementia in developing countries: Prevalence, management, and risk factors. Lancet Neurol 7: 812-826, 2008.

16. Schmidt-Kastner R, Aguirre-Chen C, Saul I, Yick L, Hamasaki D, Busto R and Ginsberg MD: Astrocytes react to oligemia in the forebrain induced by chronic bilateral common carotid artery occlusion in rats. Brain Res 1052: 28-39, 2005.

17. Jing Z, Shi C, Zhu L, Xiang Y, Chen P, Xiong Z, Li W, Ruan Y and Huang L: Chronic cerebral hypoperfusion induces vascular plasticity and hemodynamics but also neuronal degeneration and cognitive impairment. J Cereb Blood Flow Metab 35: 1249-1259, 2015.

18. Kim SK, Cho KO and Kim SY: White matter damage and hippocampal neurodegeneration induced by permanent bilateral occlusion of common carotid artery in the rat: Comparison between Wistar and Sprague-Dawley strain. Korean J Physiol Pharmacol 12: 89-94, 2008

19. Hai J, Wan JF, Lin Q, Wang F, Zhang L, Li H, Zhang L, Chen YY and $\mathrm{Lu} \mathrm{Y}$ : Cognitive dysfunction induced by chronic cerebral hypoperfusion in a rat model associated with arteriovenous malformations. Brain Res 1301: 80-88, 2009.

20. Baek SS and Kim SH: Treadmill exercise ameliorates symptoms of Alzheimer disease through suppressing microglial activation-induced apoptosis in rats. J Exerc Rehabil 12: 526-534, 2016

21. Heo YM, Shin MS, Kim SH, Kim TW, Baek SB and Baek SS: Treadmill exercise ameliorates disturbance of spatial learning ability in scopolamine-induced amnesia rats. J Exerc Rehabil 10: 155-161, 2014.

22. Seo TB, Kim BK, Ko IG, Kim DH, Shin MS, Kim CJ, Yoon JH and Kim H: Effect of treadmill exercise on Purkinje cell loss and astrocytic reaction in the cerebellum after traumatic brain injury. Neurosci Lett 481: 178-182, 2010.

23. Larsen JO, Skalicky M and Viidik A: Does long-term physical exercise counteract age-related Purkinje cell loss? A stereological study of rat cerebellum. J Comp Neurol 428: 213-222, 2000.

24. National Research Council: Guide for the care and use of laboratory animals. National Academies Press, Washington DC, 2010.

25. Shin MS, Park SS, Lee JM, Kim TW and Kim YP: Treadmill exercise improves depression-like symptoms by enhancing serotonergic function through upregulation of 5-HT1A expression in the olfactory bulbectomized rats. J Exerc Rehabil 13: 36-42, 2017.

26. Zhang Y, Cao RY, Jia X, Li Q, Qiao L, Yan G and Yang J: Treadmill exercise promotes neuroprotection against cerebral ischemia-reperfusion injury via downregulation of pro-inflammatory mediators. Neuropsychiatr Dis Treat 12: 3161-3173, 2016. 
27. Cho YS, Shin MS, Ko IG, Kim SE, Kim CJ, Sung YH, Yoon HS and Lee BJ: Ulinastatin inhibits cerebral ischemia-induced apoptosis in the hippocampus of gerbils. Mol Med Rep 12: 1796-1802, 2015.

28. Shin MS, Ko IG, Kim SE, Kim BK, Kim TS, Lee SH, Hwang DS, Kim CJ, Park JK and Lim BV: Treadmill exercise ameliorates symptoms of methimazole-induced hypothyroidism through enhancing neurogenesis and suppressing apoptosis in the hippocampus of rat pups. Int J Dev Neurosci 31: 214-223, 2013.

29. Celio MR: Calbindin D-28k and parvalbumin in the rat nervous system. Neuroscience 35: 375-475, 1990.

30. Cotman CW and Berchtold NC: Exercise: A behavioral intervention to enhance brain health and plasticity. Trends Neurosci 25 295-301, 2002

31. Lee JM, Park JM, Song MK, Oh YJ, Kim CJ and Kim YJ: The ameliorative effects of exercise on cognitive impairment and white matter injury from blood-brain barrier disruption induced by chronic cerebral hypoperfusion in adolescent rats. Neurosci Lett 638: 83-89, 2017.

32. Schefer V and Talan MI: Oxygen consumption in adult and Aged $\mathrm{C} 57 \mathrm{Bl} / 6 \mathrm{~J}$ mice during acute treadmill exercise of different intensity. Exp Gerontol 31: 387-392, 1996.

33. Kwon SJ, Park JS, Park SY, Song KS, Jung ST, Jung SB, Park IR, Choi WS and Kwon SO: Low-intensity treadmill exercise and/or bright light promote neurogenesis in adult rat brain. Neural Regen Res 8: 922-929, 2013.

34. Shimada H, Hamakawa M, Ishida A, Tamakoshi K, Nakashima $H$ and Ishida K: Low-speed treadmill running exercise improves memory function after transient middle cerebral artery occlusion in rats. Behav Brain Res 243: 21-27, 2013.

35. Alaei H, Moloudi R and Sarkaki AR: Effects of treadmill running on mid-term memory and swim speed in the rat with Morris water maze test. J Bodyw Mov Ther 12: 72-75, 2008.

36. Sim YJ: Treadmill exercise alleviates impairment of spatial learning ability through enhancing cell proliferation in the streptozotocin-induced Alzheimer's disease rats. J Exerc Rehabil 10 : 81-88, 2014.

37. Liddelow SA, Guttenplan KA, Clarke LE, Bennett FC, Bohlen CJ, Schirmer L, Bennett ML, Münch AE, Chung WS, Peterson TC, et al: Neurotoxic reactive astrocytes are induced by activated microglia. Nature 541: 481-487, 2017.

38. Kim M, Shin MS, Lee JM, Cho HS, Kim CJ, Kim YJ, Choi HR and Jeon JW: Inhibitory effects of isoquinoline alkaloid berberine on ischemia-induced apoptosis via activation of phosphoinositide 3-kinase/protein kinase B signaling pathway. Int Neurourol J 18: 115-125, 2014

39. Bruce AJ, Boling W, Kindy MS, Peschon J, Kraemer PJ, Carpenter MK, Holtsberg FW and Mattson MP: Altered neuronal and microglial responses to excitotoxic and ischemic brain injury in mice lacking TNF receptors. Nat Med 2: 788-794, 1996.
39. Vilhardt F: Microglia: Phagocyte and glia cell. Int J Biochem Cell Biol 37: 17-21, 2005.

40. Cho HS, Kim TW, Ji ES, Park HS, Shin MS and Baek SS: Treadmill exercise ameliorates motor dysfunction through inhibition of Purkinje cell loss in cerebellum of valproic acid-induced autistic rats. J Exerc Rehabil 12: 293-298, 2016.

41. Lee JM, Shin MS, Ji ES, Kim TW, Cho HS, Kim CJ, Jang MS, Kim TW, Kim BK and Kim DH: Treadmill exercise improves motor coordination through ameliorating Purkinje cell loss in amyloid beta23-35-induced Alzheimer's disease rats. J Exerc Rehabil 10: 258-264, 2014.

42. Seo TB, Kim TW, Shin MS, Ji ES, Cho HS, Lee JM, Kim TW and Kim CJ: Aerobic exercise alleviates ischemia-induced memory impairment by enhancing cell proliferation and suppressing neuronal apoptosis in hippocampus. Int Neurourol J 18: 187-197, 2014.

43. Marques-Aleixo I, Santos-Alves E, Balça MM, Rizo-Roca D, Moreira PI, Oliveira PJ, Magalhães J and Ascensão A: Physical exercise improves brain cortex and cerebellum mitochondrial bioenergetics and alters apoptotic, dynamic and auto(mito)phagy markers. Neuroscience 301: 480-495, 2015.

44. Kim JE, Shin MS, Seo TB, Ji ES, Baek SS, Lee SJ, Park JK and Kim CJ: Treadmill exercise ameliorates motor disturbance through inhibition of apoptosis in the cerebellum of valproic acid-induced autistic rat pups. Mol Med Rep 8: 327-334, 2013.

45. Kántor O, Schmitz C, Feiser J, Brasnjevic I, Korr H, Busto R, Ginsberg MD and Schmidt-Kastner R: Moderate loss of cerebellar Purkinje cells after chronic bilateral common carotid artery occlusion in rats. Acta Neuropathol 113: 549-558, 2007.

46. Meng Y, Li WZ, Shi YW, Zhou BF, Ma R and Li WP: Danshensu protects against ischemia/reperfusion injury and inhibits the apoptosis of $\mathrm{H} 9 \mathrm{c} 2$ cells by reducing the calcium overload through the p-JNK-NF-кB-TRPC6 pathway. Int J Mol Med 37: 258-266, 2016.

47. Barski JJ, Hartmann J, Rose CR, Hoebeek F, Mörl K, Noll-Hussong M, De Zeeuw CI, Konnerth A and Meyer M: Calbindin in cerebellar Purkinje cells is a critical determinant of the precision of motor coordination. J Neurosci 23: 3469-3477, 2003.

48. Gandhi CC, Kelly RM, Wiley RG and Walsh TJ: Impaired acquisition of a Morris water maze task following selective destruction of cerebellar purkinje cells with OX7-saporin. Behav Brain Res 109: 37-47, 2000.

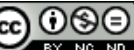

This work is licensed under a Creative Commons Attribution-NonCommercial-NoDerivatives 4.0 International (CC BY-NC-ND 4.0) License. 